\title{
Practice Plan are there for you every step of the way
}

\author{
Regional Support Manager, Josie Hutchings, explains how the team at Practice Plan are there for you every step \\ of the way when you decide to make the move from NHS to private dentistry.
}

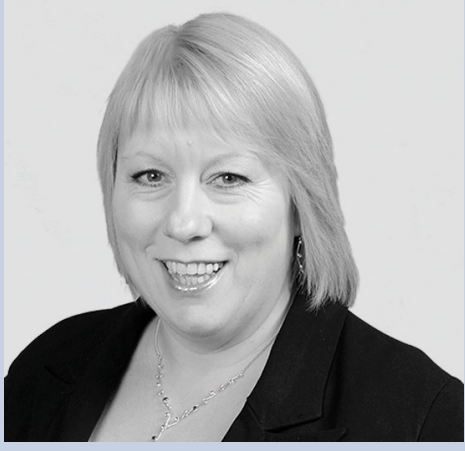

Josie Hutchings

It is a fact that many dentists are currently feeling disillusioned, and as a result stressed, with the restrictions that come with working under the NHS and have started to think about a future in private dentistry however, for some, making the move is a step into the unknown.

At Practice Plan, our team of Regional Support Managers (RSMs) have assisted hundreds of different practices in making that first step to a life in private dentistry and helped them to enjoy a more balanced and rewarding life away from the NHS.

One of the first things we'll do at Practice Plan, in the event you contact us to discuss making the move to private practice, is to take you through what the conversion process entails and present you with a wealth of information and advice that will ease any initial worries you might have about making the move.

We will hold your hand and support you through the journey, and when you have pressed the button on the move and realised your dream of becoming a private practice, we'll continue to be there supporting and helping you to grow and maintain a profitable practice.

\section{The first conversation}

If you're seriously considering life outside of the NHS and are seeking a move to private dentistry, the first thing we'd encourage you to do is pick up the phone and contact an
NHS to private conversion specialist, such as Practice Plan.

Our team of RSMs have years of experience in supporting practices through this transition and will be happy to set up a meeting at a place and time that is convenient for you. During that meeting, we will seek to gain an understanding of your individual situation, before explaining what your options are and what the journey from NHS to private involves. What myself and our other RSMs also do is present you with case studies, showing you other practices that thought long and hard about making the change, made it and are now flourishing as a private practice.

Following this meeting, you will have all the information you'll need to make your own informed decision about whether you want to move away from the NHS, and whether you want to go through a partial or full conversion.

\section{Handing back your NHS contract and getting the ball rolling}

One of the first things that we help you with is handing back your NHS contract. Whether you're handing back all of it, or just part of it, for some, dealing with the Local Area Team (LAT) can be worrying. However, our RSMs have years of experience in dealing with this part of the conversion.

We can help you with all the correspondence, and advise you on what to say and how to deal with the LAT. The majority of the time, the process will go smoothly, although sometimes certain tricky scenarios arise when handing back a contract. However, as RSMs, we have been through this process hundreds of times and have dealt with a variety of different situations with a number of different LATs, so we have a wealth of experience in dealing with contracts.

\section{Talking to patients and staff}

We spend a lot of time with all practice staff talking them through the process and making sure they are all on the same page, because it is not just the principal or the associates making the move, it is the whole practice.

As part of our support, we'll come into the practice and spend time with your team explaining why you're making the move and what the benefits are going to be for the staff and the patients. We'll also take the team through the process step by step, as our experience has shown that if we make the time to go through everything with your staff, it helps to alleviate any concerns they may have about the conversion, and it also puts you in the best position to convert as many of your NHS patients to a membership plan as possible.

What we also do is provide the members of your team with extensive training to allow them to do the same when it comes to informing the patients. We will teach them and give them tips and techniques, so they feel comfortable having that conversation with your patients.

\section{Ongoing support}

Although there may be an end date in terms of when the conversion is complete, there is never an end date with regards to the support you can receive from your RSM and wider Practice Plan family. Well beyond the point you become a private practice, your RSM and wider supporting teams will be there for you.

Practice Plan has extensive support available that focuses on helping you to grow your practice and challenges you to look at things differently. In fact, many practices find our comprehensive programme of events, workshops and webinars invaluable, with many of these aimed at helping you to grow your membership plan and expand your practice.

Whatever the level of support you need, your RSM will be on hand. In many cases, practices describe their RSM as an extended member of their team, rather than someone who works for Practice Plan. Although we might not be needed to hold your hand beyond the end of the conversion, we're always there to help and support you in whatever way we can.

Josie is a Regional Support Manager for Practice Plan with over 20 years of experience. 